\title{
ALTERAÇÕES NAS ATIVIDADES DAS ENZIMAS ALFA-GALACTOSIDASE E POLIGALACTURONASE E NAS RESERVAS DE CARBOIDRATOS DE SEMENTES DE Schizolobium parahyba (VELL.) BLAKE (GUAPURUVÚ) DURANTE A GERMINAÇÃO.
}

\author{
SIMONE RODRIGUES DE MAGALHÃES ${ }^{1}$; EDUARDO EUCLYDES DE LIMA E BORGES; \\ ANA PAULA AGUIAR BERGER ${ }^{3}$
}

\begin{abstract}
RESUMO - A retomada do metabolismo do embrião durante a germinação é realizada por processos metabólicos que culminam na protrusão da radícula e no fornecimento de energia para o desenvolvimento inicial da plântula. O objetivo deste trabalho foi estudar as variações nas atividades das enzimas alfa-galactosidase e poligalacturonase e nas reservas de mono e oligossacarídeos em sementes de guapuruvú durante a germinação. Para tanto, as sementes foram colocadas para germinar e as reservas do eixo embrionário e cotilédones, avaliadas periodicamente. Os teores de galactose no eixo embrionário diferiram significativamente somente entre a testemunha e o oitavo dia, muito embora houvesse aumento contínuo até o quarto dia. Somente no sexto dia de germinação houve aumento no teor de galactose nos cotilédones. Houve tendência de aumento nos teores de arabinose, manose e glicose no eixo embrionário, não sendo detectada a presença de xilose no oitavo dia. Nos cotilédones os mesmos açúcares não foram originalmente detectados no tempo zero, mas apresentaram valores mais altos nas amostras do oitavo dia. Os teores de galactose oscilam tanto no eixo embrionário, quanto nos cotilédones durante o período de germinação de sementes de guapuruvu. Os teores de sacarose aumentam e os de rafinose decrescem nos cotilédones e no eixo embrionário. Os teores de estaquiose permanecem aproximadamente estáveis no eixo e nos cotilédones, com decréscimo no eixo, no oitavo dia. A enzima alfa-galactosidase é pré-formada, tendo clara redução na sua atividade específica, no segundo dia, permanecendo constante até o oitavo. A atividade nos cotilédones apresenta aumento no quarto dia, decrescendo posteriormente. A enzima polygalacturonase é tambem pré-formada, com maior atividade inicial no eixo. A atividade nos cotilédones aumenta até o sexto dia, alcançando maiores valores que o do eixo embrionário e, em seguida, decresce para valores menores do que aqueles.
\end{abstract}

Termos para indexação: fisiologia, metabolismo, monossacarídeo, oligossacarídeo, enzimas.

Submetido em 02/10/2008. Aceito para publicação, 05/04/2009.

${ }^{1}$ Bolsista PIBIC/CNPq, Graduação em Engenharia Florestal, Universidade Federal de Viçosa, Avenida Peter Henry Rolfs s/n, CEP 36571-000 Viçosa, Minas Gerais, Brasil.simagalhaes@gmail.com

${ }^{2}$ Engenheiro Florestal, Dr., Professor Adjunto, Departamento de Engenharia
Florestal, Universidade Federal de Viçosa, Avenida Peter Henry Rolfs s/n, CEP 36571-000 Viçosa, Minas Gerais, Brasil. elborges@ufv.br

${ }^{3}$ Bióloga. Ms. Universidade Federal de Viçosa, Avenida Peter Henry Rolfs s/n, CEP 36571-000 Viçosa, Minas Gerais, Brasil. anapaula.berger@ gmail.com 


\author{
CHANGES IN THE ACTIVITIES OF ALPHA-GALACTOSIDASE AND \\ POLYGALACTURONASE ENZYMES AND CARBOHYDRATE RESERVES DURING \\ GERMINATION OF Schizolobium parahyba (VELL.) BLAKE SEEDS
}

\begin{abstract}
The restart metabolism of the embryo during germination is carried out by metabolic processes that culminate in root protrusion and energy supply for the initial seedling development. Thus, the objective of this study was to investigate changes in the activity of the polygalacturonase and alpha-galactosidase enzymes and the mono and oligosaccharides reserves during germination of Schizolobium parahyba seeds. Seeds were placed in petri dishes to germinate and samples were removed periodically for analyses. The galactose levels in the embryonic axis differed significantly only between the treatment control and the eighth day sample, although continuous increase occurred until the fourth day. There was an increase in the amount of galactose in the cotyledons only on the sixth day of germination; on other days the values were similar. Levels of arabinose, mannose and glucose tended to increase in the embryonic axis and the presence of xylose was not detected on the eighth day. The same sugars were not originally detected at time zero in the cotyledons, but other samples presented their highest values on the eighth day. The sucrose levels increased in the axis and cotyledons, while those of raffinose decreased in both. The stachiose concentration remained relatively constant in the axis and cotyledons until the sixth day and then decreased in the axis on the eighth day. The enzyme alpha-galactosidase was pre-formed and was reduced in its specific activity as of the second day and remaining constant until the eighth day. Activity in cotyledons varied throughout the analysis period. Polygalacturonase was also a pre-formed enzyme, with most of its activity in the axis. The activity in the cotyledons increased until the sixth day, reaching larger values than those of the axis, and then decreased to values below that observed in the axis.
\end{abstract}

Index terms: physiology, metabolism, monosaccharide, oligosaccharide, enzymes.

\section{INTRODUÇÃO}

Os compostos de reserva presentes nas sementes são responsáveis pelo crescimento inicial da plântula até que ela possa realizar fotossíntese, sendo fonte de energia para manter os processos metabólicos em funcionamento e de matéria para a formação de novas estruturas (Carvalho \& Nakagawa, 2000; Buckeridge et al., 1999).

Muitos estudos têm sido focados na análise da composição química das reservas de sementes, visando não apenas conhecer as propriedades nutricionais, mas também as características físico-químicas especiais dos componentes que formam soluções altamente viscosas, com diversas aplicações na indústria alimentícia, cosmética e farmacêutica (Buckeridge et al., 2004a).

Os carboidratos estão dentre os compostos de reserva com maior proporção nas sementes (Corte et al., 2006), sendo fonte de energia e de carbono para suprir o desenvolvimento inicial da plântula (Marcos filho, 2005; Buckeridge et al., 2004b). O teor das reservas pode variar entre espécies, mesmo dentro da própria família (Marcos Filho, 2005; Bewley \& Black, 1994; Borges \& Rena, 1993).

Os carboidratos pré-formados servem como substrato para a respiração na fase inicial da germinação. Além disto, estes compostos são considerados eficientes para promover a estabilização de estruturas das membranas durante a maturação (Obendorf, 1997). Em sementes de Sesbania marginata os oligossacarídeos da série rafinósica foram quebrados durante o processo de embebição, havendo uma relação do pico de atividade das hidrolases do endosperma com a germinação (Buckeridge \& Dietrich, 1996). Em Trigonella goenum-graecum as reservas do endosperma foram mobilizadas, resultando em incrementos de glicose, frutose e sacarose no eixo embrionário (Dirk et al., 1999). Segundo Tiné et al. (2000), os polissacarídeos são degradados após a germinação, entre 35 e 55 dias do plantio.

A germinação se inicia com a embebição das sementes, estimulando a síntese de enzimas ou a ativação daquelas 
pré-existentes, resultando na mobilização de reservas e na digestão da parede celular, enfraquecendo-a e permitindo que a raiz rompa o tegumento (Baskin \& Baskin, 1998; Borges \& Rena, 1993). Dentre as enzimas envolvidas na germinação as alfa-galactosidases, que atuam nos polissacarídeos de manose, têm sido citadas na literatura como responsáveis pelo amolecimento do tegumento, embora, Borges et al. (2002) observassem que a alfa-galactosidase não está relacionada com as alterações na composição da parede celular ou nos teores de monossacarídeos em sementes de Platimiscium pubescens.

A poligalacturonase é uma hidrolase importante para a degradação de pectinas, tendo sido reportada como a responsável pelo amolecimento do tegumento em sementes de Lycopersicon esculentun, resultando na protrusão da radícula (Sitrit et al., 1999).

Diante dos estudos citados, observa-se que estas informações são importantes para a pesquisa básica, além de grande valia para o manejo das sementes, seja para cultivos comerciais, seja para medidas de reflorestamento e preservação da espécie.

Schizolobium parahyba (Vell.) Blake (guapuruvú) é uma espécie nativa que, segundo Lorenzi (1992), ocorre na floresta pluvial atlântica dos estados da Bahia, Espírito Santo, Rio de Janeiro, São Paulo e Minas Gerais. Segundo Júnior \& Belini (2002), a madeira de guapuruvú tem potencial para produção de lâminas e manufatura de compensados, bem como o compensado de guapuruvú tem potencial para uso em móveis, embalagens e caixotaria.

Mesmo diante da importância da espécie não existe conhecimento a respeito das propriedades bioquímicas e eventos envolvidos na germinação de suas sementes. Deste modo, no presente trabalho objetivou-se estudar as atividades das enzimas alfa-galactosidase e poligalacturonase e as alterações nas reservas de carboidratos nos cotilédones e no eixo embrionário, durante a germinação.

\section{MATERIAL E MÉTODOS}

Foram utilizadas sementes de Schizolobium parahyba, coletadas de três árvores, na região de Viçosa, Minas Gerais. Os trabalhos foram conduzidos no Laboratório de Análise de Sementes Florestais do Departamento de Engenharia Florestal da Universidade Federal de Viçosa.

Durante o beneficiamento foram eliminados os frutos deteriorados e danificados, sendo acondicionados em sacos plásticos e armazenados em câmara fria a $5^{\circ} \mathrm{C}$, até a realização dos experimentos.
O teste de germinação foi realizado em placas de Petri, forradas duplamente com papel tipo germitest e umedecidos com água destilada. Primeiramente as sementes tiveram sua dormência quebrada por meio de escarificação na extremidade oposta ao embrião com lixa $\mathrm{n}^{\mathrm{o}} 80 \mathrm{e}$, em seguida, tratadas com fungicida Captan $0,5 \%$, em imersão por três minutos. Logo após, as sementes foram semeadas nas placas de Petri e mantidas em germinador, a $25^{\circ} \mathrm{C}$ sob luz contínua proporcionada por quatro lâmpadas fluorescentes de $40 \mathrm{Watts}$, tipo luz do dia.

A avaliação da velocidade de germinação foi estimada pelo Índice de Velocidade de Germinação (IVG) de acordo com Nakagawa (1994), sendo utilizadas cinco repetições de vinte sementes cada.

O teor de água foi determinado durante o período de 10 dias de embebição. As sementes foram mantidas por $24 \mathrm{~h}$ em estufa regulada à temperatura de $105^{\circ} \mathrm{C} \pm 3^{\circ} \mathrm{C}$. Utilizaram-se três repetições com cinco sementes em cada. $\mathrm{O}$ cálculo foi realizado com base no peso úmido (Brasil, 1992).

Para extração e quantificação dos carboidratos as sementes foram retiradas a cada quarenta e oito horas, até o início da protrusão da radícula, ocorrida no oitavo dia, dissecadas em tegumento, cotilédones e eixo embrionário. As amostras foram secas em estufa a $45^{\circ} \mathrm{C}$, até peso constante, moídas, acondicionadas em vidros hermeticamente fechados e mantidas congeladas $\left(-30^{\circ} \mathrm{C}\right)$ até a extração e quantificação das reservas.

As extrações de açúcares redutores e de oligossacarídeos foram feitas conforme metodologia descrita por Black et al. (1996), com modificações, utilizando-se três repetições de $0,6 \mathrm{~g}$ de amostra seca. Após cada uma das quatro extrações, a mistura foi centrifugada, retirando-se o sobrenadante, que foi usado na quantificação de monossacarídeos e oligossacarídeos.

Os monossacarídeos extraídos das sementes foram transformados em alditol acetato, para quantificação em cromatografia gasosa (Englyst \& Cummings, 1984). Os cromatogramas foram obtidos com o uso de coluna Shimadzu de $25 \mathrm{~m}$. A temperatura da coluna foi de $220^{\circ} \mathrm{C}$, a do injetor de $250^{\circ} \mathrm{C}$ e a do detector de $275^{\circ} \mathrm{C}$. Foram utilizadas três repetições.

Os oligossacarídeos foram quantificados após passagem das amostras em coluna Sep-pak C-18 e, após redução do volume, injetando $20 \mu \mathrm{L}$ em cromatografo líquido de alta performance (HPLC) Shimadzu, equipado com coluna amines HPX-42C, de $300 \mathrm{~mm} \times 7,8 \mathrm{~mm}$, tendo a água como fase móvel, com fluxo de $0,6 \mathrm{~mL} / \mathrm{min}$ e comparados com os respectivos padrões. $\mathrm{O}$ aparelho foi equipado com detector 
de índice de refração.

O extrato enzimático foi preparado imediatamente após a retirada das amostras, realizadas a cada quarenta e oito horas. A extração e quantificação da atividade das enzimas foram realizadas segundo Rezende (1998) e Viana (2002), com modificações. Uma amostra de $100 \mathrm{mg}$ de cada parte da semente, foi macerada em $1,5 \mathrm{~mL}$ de tampão acetato de sódio $100 \mathrm{mM}$, pH 5,0 em cadinho de porcelana sob gelo. Após maceração a amostra foi centrifugada a 17000rpm por 20 minutos a $4^{\circ} \mathrm{C}$, com redução de volume sob vácuo a frio. $\mathrm{O}$ sobrenadante foi utilizado para quantificar as enzimas poligalacturonase (PG), alfa-galactosidase ( $\alpha$-Gal).

Foi utilizado o para-nitrofenil-a-D-galactopiranosídeo (p-NPGal) como substrato na avaliação da atividade da alfagalactosidase. A mistura de reação constou de $750 \mathrm{~mL}$ de

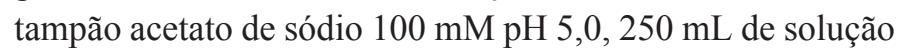
$2 \mathrm{mM}$ de p-NPGal e $10 \mathrm{~mL}$ do extrato enzimático.

Os tubos contendo a solução foram mantidos em banho maria a $37^{\circ} \mathrm{C}$ por $15 \mathrm{~min}$, sendo interrompida a reação pela adição de $1,0 \mathrm{~mL}$ de solução de $0,5 \mathrm{M}$ de $\mathrm{Na}_{2} \mathrm{CO}_{3}$. Os valores de absorbância medidos no comprimento de onda de $410 \mathrm{~nm}$ foram transformados em mmoles de -nitrofenolato (p-NP), utilizando uma curva padrão construída com 0-0,20 mmoles de p-NP. A unidade de enzima é definida como sendo a quantidade de proteína necessária para produzir um mmol de p-NP por minuto nas condições do ensaio.

A atividade da poligalacturonase foi determinada pela dosagem de açúcar redutor produzido segundo o método do DNS (3,5 dinitrossalicílico), adaptado de Miller (1959). Foi adicionada solução de ácido poligalacturônico de laranja ao extrato enzimático e incubado a $37^{\circ} \mathrm{C}$ por 30 minutos. Posteriormente, adicionou-se $1,0 \mathrm{~mL}$ de reativo de DNS e foi feita leitura em $640 \mathrm{~nm}$, sendo calculada a atividade. Os resultados foram expressos em unidades de poligalacturonase, onde uma unidade corresponde à quantidade de ácido galacturônico liberado $(\mu \mathrm{M})$ por minuto de reação $(\mathrm{U} / \mathrm{mL})$.

Utilizou-se o delineamento inteiramente ao acaso, e os dados foram analisados pelo programa Sistema de Análise Estatística (SAEG, versão 8.X, Universidade Federal de Viçosa). Quando os dados não atenderam aos pressupostos de normalidade e homocedasticidade, utilizou-se análise descritiva.

\section{RESULTADOS E DISCUSSÃO}

A porcentagem máxima de germinação foi de $88 \%$ (Figura 1). O índice de velocidade de germinação foi de 7,7. A germinação iniciou, em média, aos nove dias, estabelecendo-se o período de avaliação até o oitavo dia de embebição (Figuras 1 e 2).

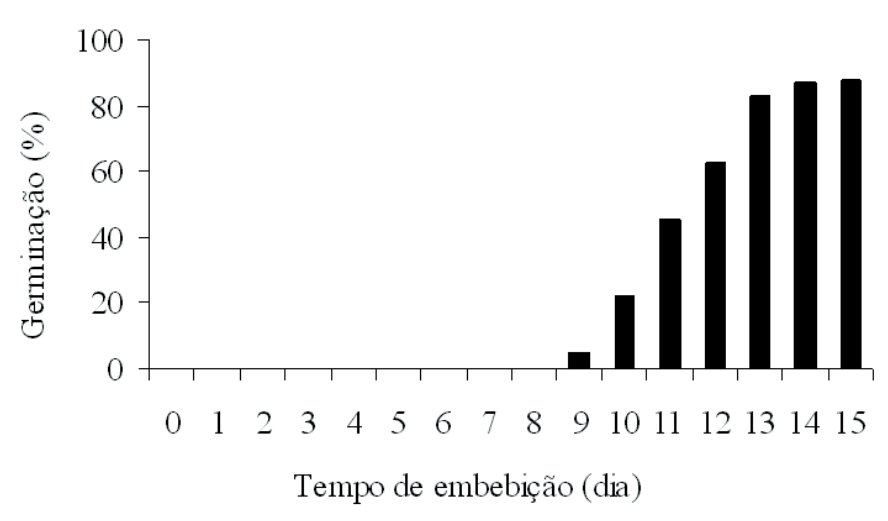

FIGURA 1. Porcentagem de germinação de sementes de Schizolobium parahyba durante o período de embebição.

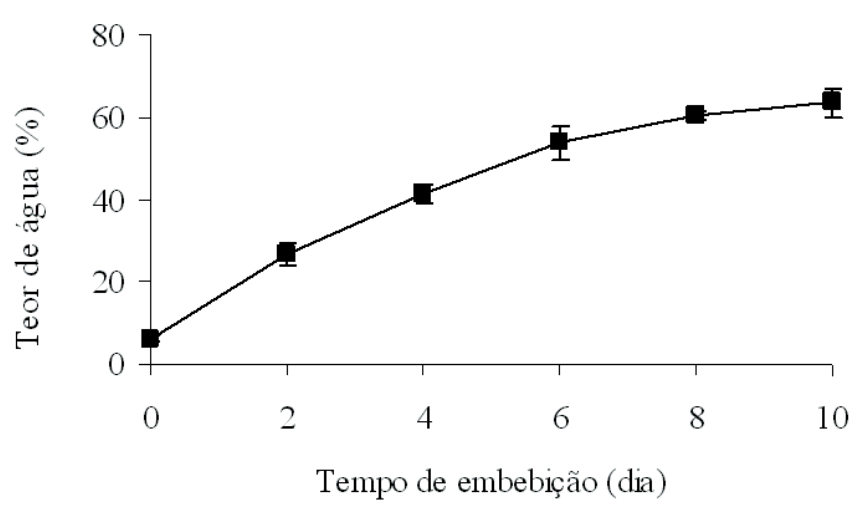

FIGURA 2. Teor médio de água em sementes de Schizolobium parahyba durante a germinção. As barras verticais representam erros padrão.

$\mathrm{O}$ alto teor de água pode ser devido, em parte, aos galactomanos presentes no gênero Schizolobium que, segundo Buckeridge et al. (1999), possui função de reserva e influencia no fluxo de água, absorvendo, proporcionalmente, grande quantidade dela. De acordo com estes autores, quanto maior o grau de ramificação, mais solúvel o polissacarídeo e maior a participação deste nas relações hídricas. Embora os galactomananos não tenham sido quantificados no presente trabalho, pode-se inferir que sejam responsáveis pela retenção de água nas sementes de $S$. parahyba durante as fases I e II da germinação. 
A galactose predominou dentre os demais cotilédones. Os demais monossacarídeos apresentaram quantidades inferiores a $0,35 \mathrm{mg} / \mathrm{g}$ massa seca. A sua produção se deu até o quarto e sexto dias de embebição no eixo embrionário e nos cotilédones, respectivamente (Figura $3)$.

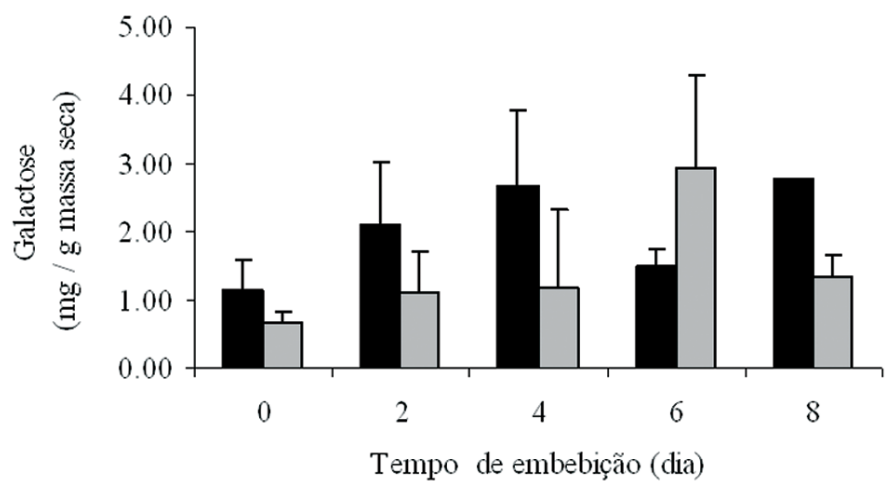

FIGURA 3. Teor médio de galactose em eixo embrionário e cotilédones em sementes de Schizolobium parahyba durante a germinação. Eixo embrionário: —,cotilédones : $\quad$. As barras verticais representam os erros padrão.

Os teores de arabinose, xilose, manose e glicose encontram-se na Figura 4. Percebe-se que somente o teor de xilose não foi detectado no eixo no oitavo dia, enquanto os
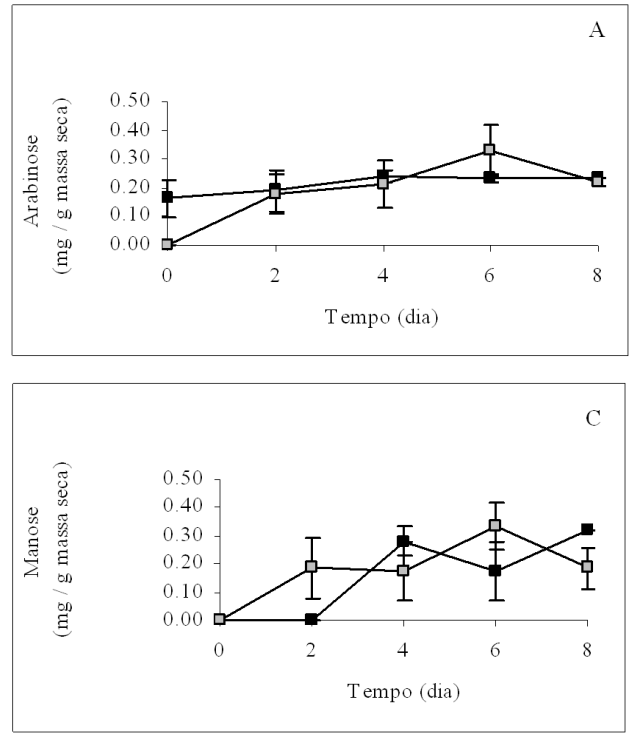
monossacarídeos, tanto no eixo embrionário como nos

demais tiveram seus teores aumentados. Não foi detectada a presença de qualquer um dos monossacarídeos nos cotilédones das sementes secas, com exceção da glicose. Pelas variações nos teores de todos eles, em cada um dos compartimentos, percebe-se que não houve, aparentemente, interação entre ambos. Pelas variações nos erros padrões da média nos cotilédones no sexto dia é possível inferir que os teores não tiveram variações com diferenças consideráveis daqueles observados no segundo dia de germinação. As mesmas considerações podem ser feitas em relação ao eixo embrionário.

Resultados obtidos por Buckeridge et al., (1995), mostraram que houve aumento constante dos açucares redutores durante a germinação no eixo embrionário e endosperma de sementes de Dimorphandra mollis.

A sacarose e a rafinose são os carboidratos predominantes em ambos os compartimentos (Figura 5). O teor médio de sacarose aumentou durante o período de embebição, com predominância no eixo, onde dobrou o seu conteúdo. A rafinose, com teores no eixo próximos aos da sacarose em sementes secas, é o primeiro e o principal oligossacarídeo utilizado pelas sementes durante a germinação, mantendose constante até o quarto dia, decrescendo em seguida para valores de um terço menor. Comportamento similar é observado nos cotilédones, com diferença de valores menores entre o primeiro e último dias em relação àquele. A estaquiose, com os menores teores dentre os três, possui comportamento próximo ao da rafinose em todos os dias de análise.
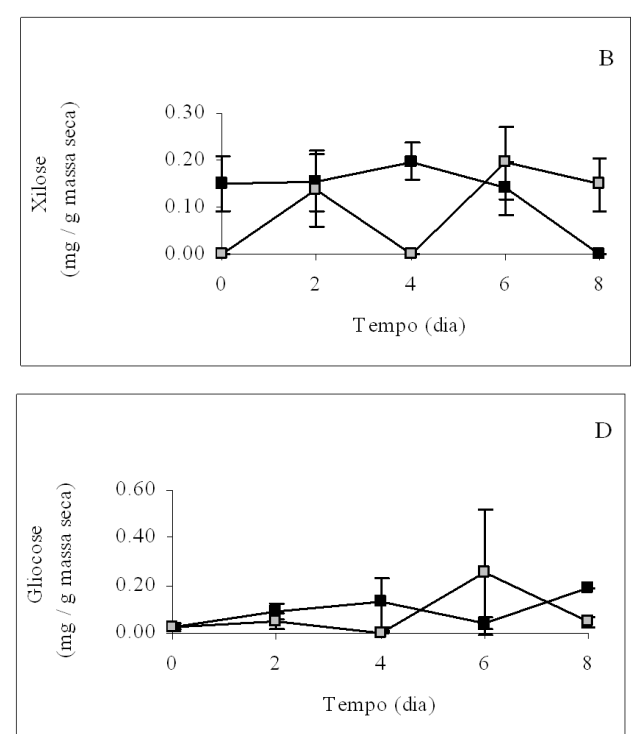

FIGURA 4. Teor médio de monossacarídeos em eixo embrionário e cotilédones em sementes de Schizolobium parahyba durante a germinação. Eixo embrionário $(\square)$ e nos cotilédones $(\square)$. Arabinose: A, xilose: B, manose: C, glicose: $\mathrm{D}$. As barras verticais representam os erros padrão. 

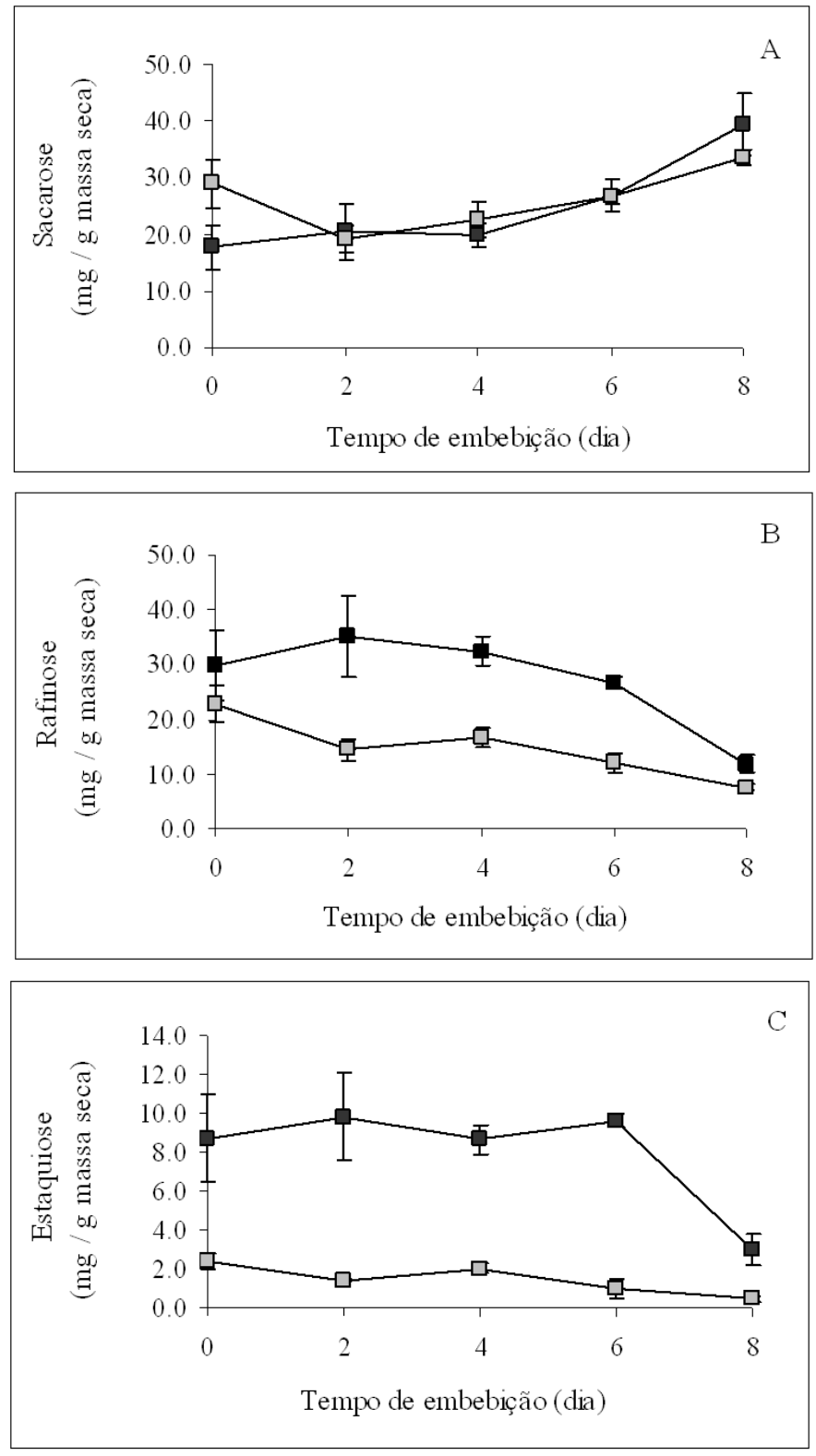

FIGURA 5. Teores médios de oligossacarídeos em eixo embrionário e cotilédones em sementes de Schizolobiumparahybaduranteagerminação. Sacarose (A), rafinose (B) e estaquiose (C). Eixo embrionário: $\square$, cotilédones: $\square$. As barras verticais representam erros padrão.

A galactose que constitui um dos componentes da rafinose e estaquiose não foi detectada em nenhum dos compartimentos indicando que foi eliminada do meio ou rapidamente utilizada para algum fim relacionado ao crescimento do eixo embrionário. A glicose, que teve sua concentração baixa nos dois compartimentos, foi, aparentemente, utilizada na síntese de sacarose. A interconversão entre a glicose e outros açúcares não parece ter ocorrido, tendo em vista os valores simultaneamentes crescentes ou decrescentes entre aqueles analisados.

Resultados obtidos por Buckeridge \& Dietrich (1996) durante a germinação de sementes de Sesbania maginata, mostrou degradação dos oligossacarídeos da série rafinósica resultando em acúmulo transitório de galactose e sacarose livres, no endosperma e eixo embrionário.

A alfa-galactosidase está ativa nas sementes quiescentes, diminuindo continuamente no eixo embrionário (Figura 6). Nos cotilédones a atividade diminui até o segundo dia e aumenta até o quarto dia de embebição, onde volta a diminuir até o final do período avaliado. Pela análise dos teores de galactose nos cotilédones, percebe-se que há correlação da atividade da enzima e dos teores do açúcar. A mesma relação ocorre no eixo onde os teores de galactose alcançam um patamar em 48 horas, similar à atividade da enzima. Pelos altos teores de galactose no embrião é de se supor que apesar de ser forte inibidor competitivo da alfagalactosidase (Guimarães et al., 2001), a galactose não esteja sendo eliminado ou metabolisado.

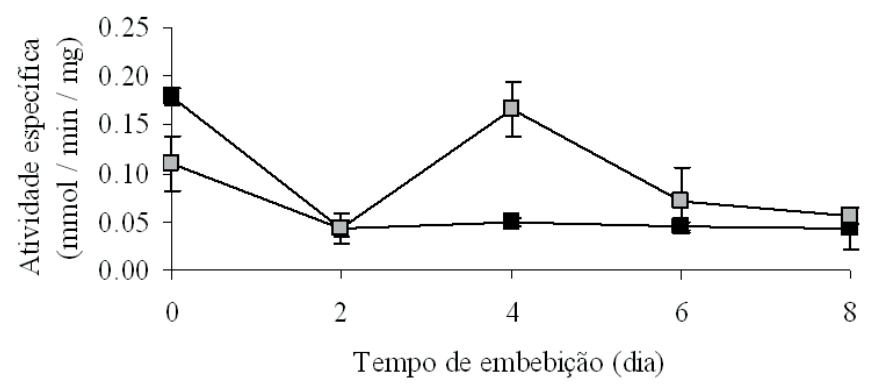

FIGURA 6. Atividade específica da alfa-galactosidase no eixo embrionário e nos cotilédones em sementes de Schizolobium parahyba durante a germinação. Eixo embrionário cotilédones: . As barras verticais representam erros padrão.

Similarmente a esta espécie, em sementes de Caelsalpinia peltophoroides, a atividade enzimática está presente mesmo antes do início da embebição e nos cotilédones teve aumento constante durante a germinação (Borges et al., 2005), 
enquanto em sementes de Platymiscium pubescens e Senna macranthera as atividades específicas decresceram no início do período de embebição (Oliveira, 2005).

Os resultados da atividade média da poligalacturonase no eixo embrionário e cotilédones estão apresentados na Figura 7. A enzima está ativa mesmo antes da embebição e sua atividade ao longo do tempo é similar em ambos os compartimentos, sendo maior no eixo embrionário de sementes secas. A atividade decresce até $48 \mathrm{~h}$ e volta a subir até o sexto dia, onde novamente diminui. Em sementes de Dalbergia nigra, a atividade da poligalacturonase apareceu no início do período de embebição, não estando presente nas sementes secas. No período anterior à protrusão da radícula a atividade da enzima nos cotilédones foi maior que no eixo embrionário, assim como observado no presente trabalho (Pontes, 2008).

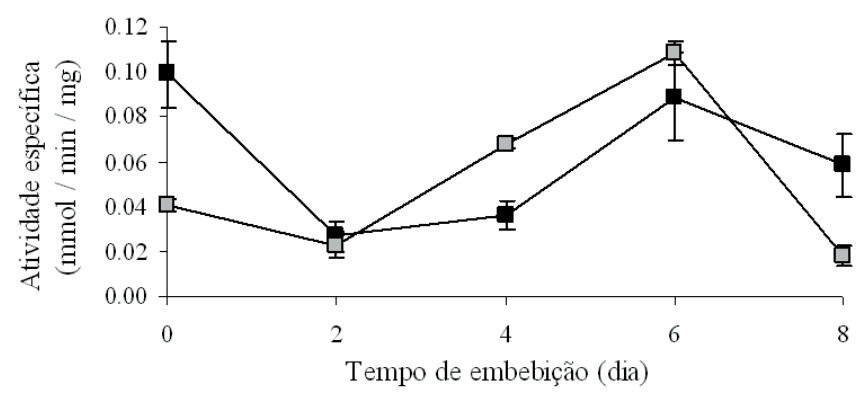

FIGURA 7. Atividade específica da poligalacturonase no eixo embrionário e nos cotilédones em sementes de Schizolobium parahyba durante a germinação. Eixo embrionário: , cotilédones: $\square$. As barras verticais representam erros padrão.z

A poligalacturonase é uma das enzimas responsáveis pelo amolecimento dos frutos durante o amadurecimento, atuando na dissolução da pectina (Lang \& Dornenburg, 2000; Brownleader et al., 1999). Dessa forma, o aumento da atividade durante a embebição, especialmente nos cotilédones, sugere que a poligalacturonase esteja causando a perda de coesão entre as células e dissolução das paredes celulares, permitindo o ataque de outras enzimas nas reservas do citoplasma. O aumento da atividade observado no eixo próximo da germinação, seis a oito dias, permitiria o crescimento do eixo embrionário devido à remoção do ácido poligalacturônico, facilitando a expansão celular, tanto pela redução da resistência da parede celular à entrada de água e mesmo a divisão celular.

\section{CONCLUSÕES}

Os teores de galactose oscilam tanto no eixo embrionário, quanto nos cotilédones durante o período de germinação de sementes de guapuruvu.

- Os teores de sacarose aumentam e os de rafinose e de estaquiose decrescem nos cotilédones e eixo embrionário. Os teores de estaquiose variam no eixo, com decréscimo nos cotilédones.

- A a enzima alfa-galactosidase é pré-formada, tendo clara redução na sua atividade específica, no segundo dia, permanecendo constante até o oitavo. A atividade nos cotilédones apresenta aumento no quarto dia, decrescendo posteriormente.

- A atividade da poligalacturonase no eixo embrionário e nos cotilédones varia durante o período de germinação de sementes de guapuruvu.

\section{REFERÊNCIAS}

BASKIN, C.C.; BASKIN, J.M. Seeds: ecology, biogeography and evolution of dormancy and germination. San Diego: Academic Press, 1998, 666p.

BLACK, M.; CORBINEAU, F.; GRZESIK, M.; GUY, P.; CÔME, D. Carbohydrate metabolism in the developing and maturing wheat embryo in relation to is desiccation tolerance. Journal Experiment of Botanic, v. 47, n. 295, p. 161-169, 1996.

BEWLEY, J.D.; BLACK, M. Seeds: physiology of development and germination. 2 ed. New York: Plenum, 1994, 445p.

BORGES, E. E. L.; RENA, A. B. Germinação de sementes. In: AGUIAR. I. B.; PIÑA-RODRIGUES, F. C. M.; FIGLIOTA, M. B. Sementes florestais tropicais. Brasília, DF: Associação Brasileira de Tecnologia de Sementes: Comitê Técnico de Sementes Florestais, 1993. 350p.

BORGES, E. E. L.; PEREZ, S. J. G. A.; BORGES, R, C, G; REZENDE, S. T.; GARCIA, S. R. Comportamento fisiológico de sementes osmocondicionadas de Platymiscium pubescens Micheli (tamboril-da-mata). Revista Árvore, v. 26, n. 5, p. 603-613, 2002.

BORGES, E. E. L.; REZENDE, S. T.; BORGES, R. C. G.; PEREZ, S. C. J. G. A. Caracterização de alfagalactosidase e sua relação com germinação das sementes de Caesalpinia peltophoroides (Leguminosae Caesalpinioideae). Revista Árvore, Viçosa, v.29, n.4, p.525-533, 2005. 
BRASIL. Ministério da Agricultura. Regras para análise de sementes. Brasília, DF: NDA/DNDV/CLAV, 1992. 365p.

BROWNLEADER, M. D.; JACKSON, P.; MOBASHERI, A. et al. Molecular aspects of cell wall modifications during fruit ripening. Critical Reviews in Food Science and Nutrition, v.39, p.149-164, 1999.

BUCKERIDGE, M. S.; DIETRICH, S. M. C. Mobilization of the raffinose family oligosaccharides and galactomannan in germinating seeds of Sesbania marginata Benth. (Leguminosae-Faboideae). Plant Science, v. 117, p. 33-43, 1996.

BUCKERIDGE, M. S.; PANEGASSI, V. R.; DIETRICH, S. M. C. Storage carbohydrate mobilization of Dimorphandra mollis Benth. (Leguminosae) following germination. Revista Brasileira de Botânica, v. 18, n. 2, p. 171-175, 1995.

BUCKERIDGE, M. S.; SANTOS, H. P; TINÉ, M. A. Mobilization of storage cell wall polysaccharides in seeds. Plant Physiology and Biochemistry, v. 38, n.12, p. 141156, 1999.

BUCKERIDGE, M. S.; AIDAR, M. P. M.; SANTOS, H. P.; TINÉ, M. A. S. Acúmulo de reserves. In: Org. FERREIRA, A. G.; BORGHETTI, F. Germinação: do básico ao aplicado. Porto Alegre: Artmed, 2004a. p. 31-50.

BUCKERIDGE, M. S.; SANTOS, H. P; TINÉ, M. A. S; AIDAR, M. P. M. Mobilização de reservas. In: FERREIRA, A. G.; BORGHETTI, F. (Org.). Germinação: do básico ao aplicado. Porto Alegre: Artmed, 2004b. p. 163- 185

NAKAGAWA, J. Testes de vigor baseados na avaliação das plântulas. In.: VIEIRA, R. D.; CARVALHO, N. M. (Ed.). Testes de vigor em sementes. Jaboticabal, 1994. p.49-85.

CARVALHO, N. M.; NAKAGANA, J. Sementes: ciência, tecnologia e produção. 4. ed. Jaboticabal: Funep, 2000. $258 \mathrm{p}$.

CORTE, B. V.; BORGES, E. E. L.; PONTES, C. A.; LEITE, I. T. A.; VENTRELlA, M. C.; MATHIAS, A. A. Mobilização de reservas durante a germinação das sementes de Caesalpinia peltophoroides Benth. (Leguminosae Caesalpinoideae). Revista Árvore, v.30, n.6, p.941-949, 2006.

DIRK, L. M. A.; VAN DER KROL, A. R.; VREUGDENHIL, D.; HILHORS, H. W. M.; BEWLEY, J.D. Galactomannan, soluble sugar and starch mobilization following germination of Trigonella goenum-graecum seeds. Plant Physiology and Biochemistry, v. 37, n. 1, p. 41-45, 1999.

ENGLYST, H. N.; CUMMINGS, J. H. Simplified method for the measurement of total non-start polysaccharides by gas-liquid chromatography of constituent sugars as alditol acetates. Analyst, v.109, p. 973-942, 1984.

GUIMARÃES, V.M. etal. Characterization of $\alpha$-galactosidase from germinating soybean seed and their use for hydrolysis of oligosaccharides. Phytochemistry, v.58, p. 67-73, 2001.

JÚNIOR G. B.; BELINI, U. L. Produção de lâminas e manufatura de compensados a partir da madeira de guapuruvu (Schizolobium parayba blake.) proveniente de um plantio misto de espécies nativas. Revista Cerne, v.8, n.2., p.1-16, 2002.

LANG, C.; DORNENBRURG, H. Perspectives in the biological function and the technological application of poligalacturonases. Applied Microbiology and Biotechnology, v.53, p.366-375, 2000.

LORENZI, H. Árvores brasileiras: manual de identificação e cultivo de plantas arbóreas nativas do Brasil. Nova Odessa: Platarum, 1992. 352p.

MARCOS FILHO, J. Fisiologia de plantas cultivadas. Piracicaba, 2005. v. 12, 495 p.

MILLER, G. Use of dinitrosalicylic acid reagent for determination of reducing sugar. Analytic Chemistry, 31, p. 426-428, 1959.

PONTES, C. A. Influência das enzimas $\boldsymbol{\alpha}$-galactosidase e poligalacturonase na germinação de sementes de Dalbergia nigra (leguminoseae-Papilonoidea). 2008. 55 f. Tese (Doutorado em Ciências Florestais) - Universidade Federal de Viçosa, Viçosa.

OBENDORF, R. L. Oligosaccharides and galactosly cyclitol in seed desiccation tolerance. Seed Science Research, v. 7, p.63-67, 1997.

OLIVEIRA, G.; GUIMARAES, V. M.; BORGES, E. E. L. et al. Purificação e caracterização de a-galactosidases de sementes de Platymiscium pubescens Micheli. Revista Árvore, v. 29, n. 4, p. 535-543, 2005.

REZENDE, S. T. Teores de oligossacarídeos de rafinose em soja, purificação e caracterização de invertase e alfa galactosidase de microorganismos. 1998. 166 f. Tese (Doutorado em Ciências Biológicas)- Universidade de Brasília, Brasília.

SITRIT, Y.; HADFIELD, K. A.; BENNETT, A. B.; BRADFORD, K. J.; DOWNIE, A. B. Expression of a polygalacturonase associated with tomato seed germination. Plant Physiology, v. 121, p. 419-428, 1999.

TINÉ, M. A.; CORTELAZZO, A. L.; BUCKERIDGE, M. S. Xyloglucan mobilization in cotyledons of developing plantlets of Hymenaea courbaril L. (Leguminosae-Caesalpinoideae). 
Plant Science, v.154, n. 2, p. 117-126, 2000.

VIANA, S. F. Caracterização de $\alpha$-Galactosidade de soja para hidrólise de oligossacarídeos de rafinose. 2002, 65 f. Dissertação (Mestrado em Bioquímica Agrícola) Universidade Federal de Viçosa, Viçosa. 